\title{
Biomechanical and biochemical properties of dog cartilage in experimentally induced osteoarthritis
}

\author{
ROY D. ALTMAN, JERRY TENENBAUM, LOREN LATTA, WAYNE RISKIN, \\ LUCIANO N. BLANCO, AND DAVID S. HOWELL
}

From the Arthritis Division, Department of Medicine, and Department of Orthopaedics and Rehabilitation, University of Miami School of Medicine, and the Arthritis Section, Miami Veterans Administration Medical Center, Miami, Florida, USA

SUMMARY The finding of other investigators that increased water content is often associated with signs of a torn collagen network in human osteoarthritic (OA) cartilage led to this study. In the Pond-Nuki model of post-traumatic OA experimental but not control femoral condylar cartilage showed evidence of breakdown and stiffening of collagen network as assessed by measurement of swelling properties and indentation behaviour respectively. These changes in the unstable knees occurred despite lack of erosion of that surface cartilage ascertained from carbon black mapping and history. The stiffening rather than softening change was therefore attributed to cartilage oedema of the middle and deep certilagenous zones, wherein breakdown of collagen network has been postulated to occur. Because of insignificant reduction of total hexuronate in these cartilages, a proteoglycan (PG) profile of sedimentation coefficients for aggregate (PGA) and subunit species (PGS) was analysed to see if collagen network changes in the dog preceded PG alteration. Despite minimal histological changes our results confirmed previous findings in the tibial plateau cartilage in this model, that PGA was reduced in size and PGS increased in amount. Slight enzymatic breakdown of PGs, or altered synthesis due to cellular responses to either the injury directly or to synovial inflammation, seems necessary to explain such changes in the absence of cartilage erosion.

Increasing importance has recently been ascribed to the role of a collagen network in the pathogenesis of osteoarthritis (OA), and much of the basis of this idea comes from tissue hydration studies. A consistent finding in OA cartilage in man has been a higher water content than that of control post-mortem cartilage. ${ }^{12}$ When pieces of human OA femoral head cartilage were cut into thin slices and incubated in $0.9 \%$ saline, they swelled enormously, whereas controls failed to swell. ${ }^{2}$ The latter normal samples, if treated with collagenase, provided swelling curves similar to OA samples. ${ }^{2}$ Moreover, OA samples and normal samples treated with collagenase revealed increased diffusivity as well as lower fixed charged density than normal controls. ${ }^{2}$ From these findings Maroudas and Venn postulated that in the fibrillated or collagenase-treated samples the restraining force of the collagen network against the swelling pressure caused by PGs was decreased, and hence the tissue achieved a higher degree of hydration. This occur-

Accepted for publication 28 January 1983.

Correspondence to Roy D. Altman, MD. University of Miami School of Medicine, PO Box 016960, Miami, FL 33101, USA. rence prevailed despite a lower osmotic pressure from decreased glycosaminoglycan (GAG) content. ${ }^{2}$ Some increase of collagen fibrillar water has also been postulated, as fibre bundles became disrupted in OA cartilage. ${ }^{3}$ Whether those changes occur early or late after the onset of disease could not be ascertained in man.

In the Pond-Nuki model of OA a precise time of disease onset is known. ${ }^{45}$ Increased water content was found not only in the tibial plateau but also in femoral articular cartilage at 3 weeks after section of the cruciate ligament. ${ }^{6}{ }^{7}$ This and multiple clinical. similarities to human disease made it of interest to test, first, whether in the dog as in man there is increasing swelling of OA cartilage in $0.9 \%$ saline, indicative of a disrupted collagen network. Secondly, because Kempson et al. ${ }^{8}$ showed that disrupted eroded human OA cartilage was softened compared with normal controls, we tested parameters of cartilage stiffness concurrently. Finally, the current dog model at 2-4 weeks postoperatively showed only slight, if any, reduction of hexuronate, an index of PG content. Moreover, increased extractability of PGs in 
hypertonic solutions was reported in OA cartilage in man, ${ }^{9}$ in the rabbit OA cartilage,${ }^{10}$ and variably in the Pond-Nuki tibial OA cartilage,${ }^{7}$ a result not found in the femoral samples. Thus a search for more subtle PG disturbances previously reported by the transport method of analytical ultracentrifugation in rabbits ${ }^{10}$ and $\operatorname{dogs}^{11}$ was made to determine whether collagen network and PG disturbances could be further dissociated.

\section{Materials and methods}

A NIMAL PREPARATION

Mature mongrel dogs $12-25 \mathrm{~kg}$ in weight and of both sexes were employed. The dogs were screened for OA skeletal maturity by joint $x$-rays. After routine 10-day quarantine and conventional health measures, the dogs were operated on. The right anterior cruciate ligament was cut by a $2 \mathrm{~mm}$ stab incision into the joint with a no. 11 Bard-Parker blade. The other knee served as a control. After the operation the right knee showed an anterioposterior subluxation (anterior draw sign). Animals moved about freely in well-ventilated large cages, $12 \times 6 \times 8$ feet $(3.7 \times 1.8 \times 2.4 \mathrm{~m})$. A few hours postoperatively they bore weight on the operated limb. The latter was held in external rotation and caused a limping gait.

As described previously, ${ }^{4}{ }^{5}$ the animals gained weight and remained active until they were killed 2-16 weeks postoperatively. In this period 1-2 dogs per week were killed in 2 groups, hereafter described as 'early' (2-9 weeks, 13 dogs) and 'late' (10-16 weeks, $13 \mathrm{dogs}$ ). One sham-operated dog (synovial incision without ligament severance) and one with no surgery as controls were both included in each of the 'early' and 'late' groups.

The operated as well as the control knees were radiologically assessed again just before the animals were killed, and bony spurs were observed in the animals killed at 12-16 weeks. A small piece of all the cartilage samples was subjected to morphological study. In each 'early' and 'late' group, either (1) swelling analysis and biochemical analysis on adjacent strips of cartilage, $20-50 \mathrm{mg}$ wet weight ( $7 \mathrm{dogs}$ ), or (2) dissection for study of creep compliance was carried out on the whole joint ( 6 dogs).

MORPHOLOGICAL STUDIES

On killing the dogs the knee joints were exposed by dissection, freed of surrounding tissues, and carbon black $1 \%$ in $0.9 \%$ saline was applied to the surface. Ink penetration was graded visually on the medial femoral condyles of each joint as described by Meachim, ${ }^{12}$ and all animals fell within the grade 1-2 range. Sagittal sections of cartilage were made from
2-3 sites on the weight-bearing apex of the medial femoral condyle and opposing tibial plateau at site A of McDevitt et al. ${ }^{7}$ on the tibial plateau. Tissues were fixed, decalcified, embedded, and sectioned for light microscopy after haematoxylin and eosin as well as safraninO staining. The resultant sections were classified on a scale of zero to 4+ in respect of surface roughening, loss of safranin $\mathrm{O}$ staining, and presence of cell clones as described by McDevitt et al. ${ }^{7}$ Our evaluations in these tests for tibial and femoral samples were approximately the same as reported in Table 1 of McDevitt et al. ${ }^{7}$ for 2,7 (in our study 8 weeks), and 16 weeks postoperatively for each of these criteria. There was one exception: only small fissures $(2+$ articular surface changes) occurred in femoral cartilage at any time. All tissues from both early and late lesions showed chondrocyte proliferation ( 2 or more cells per lacuna), mild surface disruption, chondrolysis, chondrocyte nuclear pyknosis, and focal reduction of safranin $\mathrm{O}$ staining around some lacunae. Osteophytes were composed of hyaline and fibrocartilage overlying a bony projection. Normal cellularity and staining were seen in all controls.

\section{MEASUREMENT OF SWELLING}

Slices of articular cartilage with approximate dimensions of $5 \times 10 \times 1 \mathrm{~mm}$ from the weight-bearing zone of the medial femoral condyle of both knees were excised as well as weight-bearing sites of tibial plateaus (site $A^{6}{ }^{7}$ ) with a Bard-Parker knife immediately after the animals were killed. The samples were wiped gently on the articular surface and patted dry on the cut edges with Kim wipes. They were then immediately placed in a sealed humidified chamber for $20 \mathrm{~min}$ of equilibration to restore any slight amount of water lost during the period of excision. This sealed chamber was humidified by exposure to a $0.9 \%$ saline bath for $30 \mathrm{~min}$ prior to the experiments. At time 0 the cartilage samples were subjected to a volume measurement and were immersed in $0.9 \%$ saline for $90 \mathrm{~min}$. Cartilage volume was measured at 30,60 , and $90 \mathrm{~min}$ after initial immersion.

For this purpose a volumetric chamber at $20^{\circ} \mathrm{C}$ was filled with mercury to the full mark by a manostat (the Manostat Corporation, New York). A volume $\left(V_{\mathrm{E}}\right)$ reading was recorded for the empty chamber. The sample of cartilage was removed from the humid chamber, patted dry, and immediately placed in the volumetric chamber. The latter was then filled with mercury to the full mark with occasional tapping of the sides to dislodge trapped air bubbles, and the volume was again recorded $\left(\mathrm{V}_{\mathrm{F}}\right)$. Calculations were:

$$
V_{t}=\left|V_{F_{t}}-V_{E_{t}}\right| \text { at time (t); } \Delta V \%=\frac{V_{t}-V_{0}}{V_{0}} \times 100
$$


where $V_{t}=$ cartilage volume at any time $(t)$ after zero time, $V_{0}=$ cartilage volume at zero time and $\Delta V \%$ is the percentage change in volume at time $(t)$ compared to $t_{0}$.

\section{BIOCHEMICAL MEASUREMENTS}

Comparative values of cartilage stiffness for the dog were derived by the following methods.

The entire knee joint was dissected so that the first metaphyseal bone specimen could be mounted, within 5-10 min of killing the animals within the indentation apparatus; the joint cartilage remained intact on the subchondral bone. All specimens were sealed in plastic bags to maintain their moisture content as near normal as possible until testing was complete. Creep deflection was measured by the method of Parsons and Black, ${ }^{13}$ modified to receive dog cartilage samples to evaluate structural behaviour of the specimen. Specimens were tested in a $100 \%$ humidity chamber at room temperature. Each specimen was then immersed in a $0.9 \%$ saline solution at room temperature, allowed to swell without stress for 30 min, and was then retested while immersed and swollen. Within this closed system an indenter (radius $\mathrm{r}=$ $2 \mathrm{~mm}$ ) was gently lowered on to the surface of the articular cartilage and produced a preload of $2 \times 10^{4}$ $\mathrm{N} / \mathrm{m}^{2}$ newtons per square metre. Its progress, as it indented the cartilage, was noted on recording paper as a deflection by means of a transducer. Deflection was monitored with time (creep test) with a constant load $(300 \mathrm{~g})$ applied to the indenter, producing a contact stress on the cartilage of $\left(2 \cdot 34 \times 10^{5} \mathrm{~N} / \mathrm{m}^{2}\right)$. Calibration runs were performed prior to each set of studies to check consistency. There was negligible shift in calibration throughout the run, and there was no measurable nonlinearity of the deflection transducers.

Indentation tests were made on the experimental joint surface within the weight-bearing areas of femoral and tibial cartilage and on mirror image sites of control cartilage. Deflection was monitored continuously from the onset of loading until a minimum of 1200 seconds. From these deflection values an apparent, instantaneous shear modulus $\mathrm{G}$ was calculated to provide comparative values of stiffness between specimens:

$$
G_{i}=\frac{P(1-v)}{4 \alpha K \omega_{i}}
$$

where $\mathrm{P}$ is the load, $v$ Poisson's ratio (assumed to be $0 \cdot 40), \alpha$ is the indenter radius, $\omega_{i}$ deflection of the indenter into the cartilage at times, and $\mathrm{K}$ a geometric scaling factor based on $v$ and cartilage thickness. The modulus at initial application of load was defined as $\mathrm{G}_{\mathrm{u}}$, the unrelaxed modulus. The relaxed modulus, $\mathrm{G}_{\mathrm{r}}$, was defined as the stiffness at infinity when the tissues are in mechanical equilibrium. $G_{r}$ was calculated for this study as the stiffness at 1200 seconds. Deflection at 1200 seconds was determined to be at least $90 \%$ maximum.

Cartilage specimens ranged in thickness from $0 \cdot 8$ to $1.1 \mathrm{~mm}$. Deflection values were measured for 8 to 10 points in time so that the shear creep compliance (reciprocal of shear modulus) could be plotted against log time to define the retardation-time spectrum. Comparison between operated and unoperated knee cartilage was made by utilising the degree of linearity, range of behaviour, slope of the retardation-time spectrum, and the intercepts of the straight-line plot of the measured points. Confidence in the methodlogy was secured by the consistently long linear region of behaviour of the retardationtime spectrum for dog cartilage, similar to that reported by Parsons and Black for rabbit cartilage. ${ }^{13}$ Control and experimental cartilage expressed similar spectra in terms of slope and range of linear behaviour. The position of the curves between control and experimental cartilage was based on the deflection instantaneously and after 1200 seconds.

Since the test apparatus developed for these experiments did not provide the frequency response and feedback control of the system utilised by Parsons and Black, ${ }^{13}$ the apparatus was verified by testing a standard material of known viscoelastic properties, polyethylene. Tests verified that values between 1 second and 1200 seconds were accurate and repeatable. The $G_{u}=8 \cdot 3 \times 10^{7}($ SD $0 \cdot 46) \mathrm{N} / \mathrm{m}^{2}$ for 8 runs. This falls within the published values of commercially available low density polyethylene $\left(6 \cdot 2-9.8 \times 10^{7}\right.$ $\mathrm{N} / \mathrm{m}^{2}$ ). Since the values within the first fraction of a second were not valid, minimum and maximum retardation times were not estimated for these tests on polyethylene or cartilage.

Statistical analyses were performed by the Student's ' $t$-test' ${ }^{\prime 4}$ in respect of cartilage swelling (Table 1), the biomechanical measurements (Table 2), the polydisperse PG profile, and the weight average sedimentation coefficients (Table 3 ).

BIOCHEMICAL PREPARATIVE AND ANALYTICAL METHODS

Extraction was performed on $20-50 \mathrm{mg}$ (wet weight) cartilage specimens with $4 \cdot 0 \mathrm{M} \mathrm{GuHCl}^{15}$ containing $100 \mathrm{mM}$ EDTA sodium (Mallinckrodt Chemical Works), $100 \mathrm{mM}$ amino hexanoic acid (Aldrich Chemical Co.), and benzamidine $\mathrm{HCl}$ (Aldrich Chemical Co.). ${ }^{16}$ Buffer solutions (pH 5.8) were prepared with $50 \mathrm{mM}$ sodium acetate.$^{17}$ After $48 \mathrm{~h}$ of retraction and $17 \mathrm{~h}$ of dialysis at $4^{\circ} \mathrm{C}$ proteoglycans (PG) were separated by ultracentrifugation at $20^{\circ} \mathrm{C}$ in a caesium chloride- $\mathrm{GuHCl}$ associative gradient for $48 \mathrm{~h}$ to prepare the A1 fraction. ${ }^{18}$ Total hexuronate 
content in tissue starting samples was determined and wet-ashed as previously described. ${ }^{19}$ Hexuronate was analysed by the carbazole method ${ }^{20}$ as modified by Bitter and Muir. ${ }^{21}$ The centrifugal studies were performed by the transport methology previously described ${ }^{22}$ and as recently modified with the introduction of gradient velocity centrifugation. ${ }^{23} \mathrm{Hex}$ uronate concentration was used to determine PG polydisperse profiles. ${ }^{22}$ From the data obtained the sedimentation coefficient distribution function $\mathrm{g}(\mathrm{s})$ was computed. ${ }^{23}$ The average PG concentration in the solution was $0.38 \mathrm{mg} / \mathrm{ml}^{23}$ The mean centrifuge setting was $w^{2} \mathrm{t} \times 2.4 \times 10^{10-1} \mathrm{rad}^{2} \mathrm{~s}^{-1}$. $^{23}$ There was complete display of characteristic polydispersity due to the low concentration of PGs.

\section{Results}

SWELLING MEASUREMENTS

The volume of experimental cartilage swelled 42 and $70 \%$ at $60 \mathrm{~min}$ and 70 and $78 \%$ for femoral and tibial

Table 1 Changes in volume and stiffness of cartilage samples following immersion in $0.9 \%$ saline

\begin{tabular}{|c|c|c|c|}
\hline $\begin{array}{l}\text { Time of } \\
\text { immersion and } \\
\text { nature of } \\
\text { sample }\end{array}$ & $\begin{array}{l}\text { Medial } \\
\text { condyle } \Delta \\
\text { volume }(\%) \\
(n=12)\end{array}$ & $\begin{array}{l}\text { Medial } \\
\text { plateau } \Delta \\
\text { volume }(\%) \\
(n=13)\end{array}$ & $\begin{array}{l}\text { Medial condyle } \\
\Delta \text { shear } \\
\text { modulus } \\
\left(G_{u}\right)(\%)^{*} \\
(n=12)\end{array}$ \\
\hline \multicolumn{4}{|l|}{$30 \mathrm{~min}$} \\
\hline Control & $20 \cdot 4 \pm 8 \cdot 0^{\dagger}$ & $20 \cdot 3 \pm 9 \cdot 2 \ddagger$ & $100 \cdot 8 \pm 33 \cdot 0 \S$ \\
\hline Experimental & $35 \cdot 5 \pm 9 \cdot 0$ & $41 \cdot 3 \pm 9 \cdot 8$ & $85 \cdot 2 \pm 37 \cdot 5$ \\
\hline \multicolumn{4}{|l|}{$60 \mathrm{~min}$} \\
\hline Control & $20 \cdot 2 \pm 6 \cdot 0 \ddagger$ & $30 \cdot 9 \pm 9 \cdot 6 \ddagger$ & \\
\hline Experimental & $42 \cdot 4 \pm 9 \cdot 5$ & $69 \cdot 7 \pm 14 \cdot 5$ & \\
\hline \multicolumn{4}{|l|}{$90 \mathrm{~min}$} \\
\hline Control & $29 \cdot 9 \pm 10 \cdot 2 \ddagger$ & $34 \cdot 7 \pm 9 \cdot 0 \ddagger$ & \\
\hline Experimental & $69 \cdot 9 \pm 14 \cdot 9$ & $77 \cdot 6 \pm 11 \cdot 3$ & \\
\hline
\end{tabular}

*Moist/immersed (See 'Methods').

† Mean \pm standard deviation.

$\ddagger$ Difference between control and OA $p<0.05$ (Student's $t$ test). $\S$ Difference between control and OA $0 \cdot 05<p<0 \cdot 10$ (Student's $t$ test). samples respectively above starting levels by $90 \mathrm{~min}$ (Table 1). In contrast, 20 and $31 \%$ increases above starting levels at 60 min were seen in control cartilages of femoral and tibial sources respectively. The cause of the 30 and $35 \%$ increases at $90 \mathrm{~min}$ in femoral and tibial controls is not clear. (A high cut surface-to-volume ratio in the tiny samples is believed to be responsible, since care was taken to prevent initial dehydration.) Differences in swelling between control and OA cartilage were significant $(p<0.05)$ in all comparisons except the $30 \mathrm{~min}$ tibial plateau samples.

\section{BIOMECHANICAL ANALYSIS}

Control cartilage with intact subchondral bone produced average shear moduli of $11 \cdot 55($ SD 4.68$) \mathrm{N} / \mathrm{m}^{2}$ $\times 10^{5}$ overall with $10 \cdot 29( \pm 3 \cdot 46) \mathrm{N} / \mathrm{m}^{2} \times 10^{5}$ in early lesions and $12 \cdot 23(\mathrm{SD} \pm 5 \cdot 70) \mathrm{N} / \mathrm{m}^{2} \times 10^{5}$ in late lesions (Table 2) while immersed. Late experimental samples could be indented only $57 \%$ as deeply as the control tissue - that is, the experimental tissue was stiffer, $\mathrm{Gu}=18.23( \pm 9.99) \mathrm{N} / \mathrm{m}^{2} \times 10^{5}$, than the normal cartilage and subchondral bone. Early experimental tissue was also stiffer but not as significantly: $\mathrm{Gu}=14 \cdot 17( \pm 6.91) \mathrm{N} / \mathrm{m}^{2} \times 10^{5}$.

The later deflection or relaxed modulus, $G_{r}$, demonstrated an increase in stiffness in the operated knee, $25 \%$ in the early lesions but only $10 \%$ in late lesions (Table 2). Control values were constant with time; $G_{r}$ early $2.82( \pm 0.819), G_{r}$ late $2.83( \pm$ 0.865 ). The drop in $G_{r}$ in the late group of animals from 3.45 to $2.98 \mathrm{~N} / \mathrm{m}^{2} \times 10^{5}$ is unexplained. The results showed dog control cartilage and bone to be slightly stiffer than rabbit cartilage as reported by Parsons and Black. ${ }^{13}$ Swollen OA cartilage was stiffer than moist $\mathrm{OA}$ cartilage, while control cartilage was only slightly affected (Table 1 ).

The retardation spectrum for control sides remained constant with time: $\mathrm{L}(\tau)$ early, 3.84 ( \pm $2 \cdot 15)$, and late, $3.69( \pm 1 \cdot 13) \mathrm{m}^{2} / \mathrm{N}-\mathrm{LN}(\mathrm{s}) \times 10^{7}$. No significant differences were found between experi-

Table 2 Viscoelastic properties of medial femoral condyles immersed in saline

\begin{tabular}{|c|c|c|c|}
\hline \multirow{3}{*}{$\begin{array}{l}\text { Time from surgery to } \\
\text { death and nature of sample }\end{array}$} & \multicolumn{2}{|c|}{ Shear modulus $\left(\mathrm{N} / \mathrm{M}^{2} \times 10^{5}\right)$} & \multirow{3}{*}{$\begin{array}{l}\text { Retardation spectrum } \\
\frac{\left(M^{2} / N-L N[s] \times 10^{-7}\right)}{L(\tau)(N)}\end{array}$} \\
\hline & \multirow{2}{*}{$\begin{array}{l}\text { Unrelaxed } \\
G_{\mathrm{u}}(N)\end{array}$} & \multirow{2}{*}{$\begin{array}{l}\text { Relaxed } \\
G_{\mathrm{r}}(N)\end{array}$} & \\
\hline & & & \\
\hline \multicolumn{4}{|l|}{ Early lesion (2-9 weeks) } \\
\hline Control & $10 \cdot 29 \pm 3 \cdot 46^{*}(12)^{\dagger}$ & $2 \cdot 82 \pm 0 \cdot 82(12) \dagger$ & $3 \cdot 84 \pm 2 \cdot 15(10)$ \\
\hline Experimental & $14 \cdot 17 \pm 6 \cdot 91$ & $3 \cdot 45 \pm 1 \cdot 51$ & $4 \cdot 10 \pm 2 \cdot 50$ \\
\hline \multicolumn{4}{|l|}{ Late lesion (10-16 weeks) } \\
\hline Control & $12 \cdot 23 \pm 5 \cdot 70(7) \ddagger$ & $2 \cdot 83 \pm 0 \cdot 87(7)$ & $3 \cdot 69 \pm 1 \cdot 13(6)$ \\
\hline Experimental & $18 \cdot 23 \pm 9.99$ & $4 \cdot 10 \pm 2 \cdot 50$ & $3.74 \pm 1.03$ \\
\hline
\end{tabular}

* Mean \pm standard deviation.

+ Difference between control and OA $0 \cdot 05<p<0 \cdot 10$ (paired Student's $t$ test).

$\ddagger$ Difference between control and OA $p<0 \cdot 05$ (paired Student's $t$ test). 
mental and control groups, though experimental groups tended to be higher: $4 \cdot 10$ early and $3 \cdot 79$ late.

Although both early and late dogs showed increase initial or unrelaxed moduli, $\mathrm{G}_{\mathrm{u}}$, only the late dogs had significant differences (Table 2). The later phase, or relaxed moduli, $\mathrm{G}_{\mathrm{r}}$, also showed increased cartilage stiffness in experimental cartilage when compared with controls but were not significantly stiffer. There did not seem to be a significant change in the degree of stiffness of either unrelaxed or relaxed deflections when early and late animals were compared.

More advanced cartilage lesions could not be tested, inasmuch as no extensive cartilage disruptions were seen. Creep deflection of tissue from isolated sham operated and unoperated dogs were within range of the control left knee values (data not shown) from operated animals.

The reliability of $G_{i}$ was tested. Large artefacts related to the calculation of $\mathrm{G}_{\mathrm{i}}$ were not apparent, as deflection values $(\omega)$ per se for OA experimental cartilage were statistically different from those for control cartilage.

\section{PG STUDIES}

The total hexuronate showed little change when control was compared with OA cartilage, which is consistent with the findings of McDevitt et al. ${ }^{6}$ Values averaged $7 \cdot 1 \pm 0.6(\mathrm{SD}) \mu \mathrm{g} / \mathrm{mg}$ wet tissue in control cartilage $(\mathrm{n}=7 \mathrm{dogs})$ and $6 \cdot 6 \pm 0 \cdot 5 \mu \mathrm{g} / \mathrm{mg}$ wet tissue in OA cartilage ( $n=7$, same animals). The percentage of hexuronate extracted was $61-71 \%(n=3)$ in controls and $64-74 \%(n=3)$ in OA cartilage.

\section{BIOCHEMICAL ANALYSIS}

Fig. 1 illustrates the comparison of typical results of centrifuging A1 preparations from $4.0 \mathrm{M} \mathrm{GuHCl}$ extracts of control and $\mathrm{OA}$ articular cartilage from the knees of a dog which had not yet developed osteophytes. The $\mathrm{g}(\mathrm{s})$ functions were bell-shaped continuous curves that registered 2 peaks of polydisperse components of the A1 complex. The reduction of PG aggregate and increase of PG monomer curves thus displayed for a dog cartilage 4 weeks postoperatively were typical of the OA cartilage A 1 fractions in the group of early lesions (Table 3 ).

In samples from 2 dogs of the early group no second polydispersity curve was seen, indicating that all or most of the PG was in monomeric form (data not shown). In dogs with later lesions polydispersity curves of OA cartilage were nearly superimposable on the control cartilage except in one animal, in which $90 \%$ of the cartilage sample was in the monomeric form. Because of evidence of postoperative bleeding and excessive experimental knee swelling in these 3 animals lacking aggregates, their results are neither presented nor reflected in the statistics.

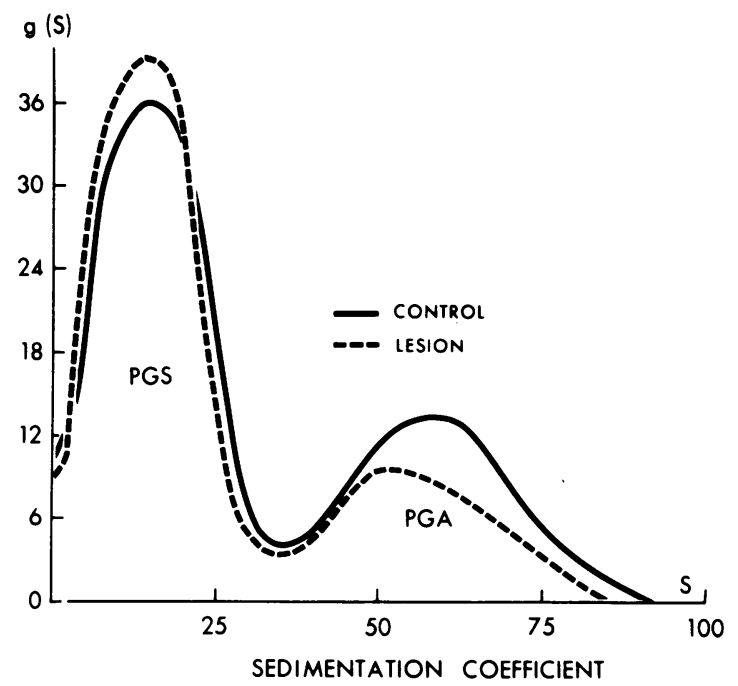

Fig. 1 (Al preparation). Representative of a dog 4 weeks postoperatively. Polydisperse PG curve of femoral cartilage $g(s)$ function corresponds to Schlieren optics pattern. Areas under each curve represent concentration of $P G$ sedimenting at $S$ values on the abscissa. Peak 1 comprises predominantly proteoglycan subunit (PGS) and peak 2 proteoglycan aggregate (PGA).

Regression analysis of paired values of control versus $O A$ profiles indicated that the largest proportional increase in PG subunits occurred within 2 weeks postoperatively, with a resolution towards control values after 10 weeks $(\mathrm{Y}=0.66, \mathrm{p}<0.05)$.

Results of weight average sedimentation coefficient (S) for A1 PG preparation from $4.0 \mathrm{M} \mathrm{GuHCl}$ extractions are reflected in Table 3 as averages for

Table 3 Ultracentrifugal analyses of articular cartilage proteoglycan aggregates (PGA) and subunits (PGS) in AI fractions*

\begin{tabular}{|c|c|c|c|c|}
\hline \multirow[t]{2}{*}{$\begin{array}{l}\text { Time from surgery } \\
\text { to death and } \\
\text { nature of sample }\end{array}$} & \multicolumn{2}{|c|}{ Polydisperse profile } & \multicolumn{2}{|c|}{$\begin{array}{l}\text { Weight average } \\
\text { sedimentation } \\
\text { coefficients }\end{array}$} \\
\hline & $P G S(1 \%)$ & $P G A(\%)$ & $P G S(S)$ & $P G A(S)$ \\
\hline \multicolumn{5}{|c|}{ Early lesion (2-9 weeks) } \\
\hline $\begin{array}{l}\text { Control } \\
\text { OA }\end{array}$ & $\begin{array}{l}65 \cdot 2 \pm 5 \cdot 3+ \\
80 \cdot 4 \pm 8 \cdot 3 \ddagger\end{array}$ & $\begin{array}{l}34 \cdot 8 \pm 5 \cdot 3 \\
19 \cdot 6 \pm 8 \cdot 3 \ddagger\end{array}$ & $\begin{array}{l}14 \cdot 7 \pm 1 \cdot 4 \\
12 \cdot 3 \pm 1 \cdot 2\end{array}$ & $\begin{array}{l}61 \cdot 8 \pm 6 \cdot 5 \\
49 \cdot 8 \pm 4 \cdot 4 \ddagger\end{array}$ \\
\hline \multicolumn{5}{|c|}{ Late lesion (10-16 weeks) } \\
\hline Controls & $69 \cdot 8 \pm 3 \cdot 0$ & $30 \cdot 2 \pm 3 \cdot 0$ & $15 \cdot 3 \pm 1 \cdot 1$ & $60 \cdot 4 \pm 2 \cdot 9$ \\
\hline $\mathrm{OA}$ & $73 \cdot 7 \pm 7 \cdot 0$ & $26 \cdot 3 \pm 7 \cdot 0$ & $15 \cdot 7 \pm 0 \cdot 3$ & $54 \cdot 2 \pm 2 \cdot 6$ \\
\hline
\end{tabular}

${ }^{*}$ Computed from area under polydisperse curves of the $\mathrm{g}(\mathrm{s})$ function. See 'Methods.' $n=6$.

+ Mean \pm Standard error.

$\ddagger$ Difference between control and OA $p<0$. (Student's $t$ test). 
each group of dogs. There was no significant reduction in $\mathrm{S}$ values of the monomers. The overall mean $\mathrm{S}$ value for monomer was $15 \cdot 0 \pm 3 \cdot 1$ (SD). These values were similar to those found in rabbit bovine articular cartilage. ${ }^{10}$ There was a small but statistically significant reduction in PG aggregates from the early lesions when compared with controls. Samples of sham operated and unoperated animals gave polydisperse profiles that were similar to control values.

\section{Discussion}

The current swelling experiments on OA cartilage add evidence to the view that the collagen network was torn in some of these samples, affording a partial explanation of the increased water content previously reported ${ }^{6}$ and a confirmation of experiments by Maroudas and Venn. ${ }^{2}$ More important is that these findings were present 4 weeks postoperatively, suggesting an early or possibly initial step in disease production rather than a late event secondary to cartilage degeneration. Secondly, because of only stage 1-2 carbon black penetration, ${ }^{12}$ representing absence of any detectable fissures or erosion extending into the radial zone, as well as absence of decline in hexuronate concentration, loss of PGs from the tissue at this stage as a factor contributing to the $\mathrm{OA}$ lesion seems to be contradicted.

Some unravelling or swelling of PGs in the middle and deep cartilage zones might be anticipated here nevertheless. A concentration gradient of GAGs running from high to low in progression toward the joint space ${ }^{24}$ has been shown, and in the middle zone the greatest swelling pressure is exerted. ${ }^{2}$ This swelling pressure would be accentuated particularly on weight bearing, inasmuch as the pressure has been shown to increase exponentially as a function of compression. ${ }^{2}$ In most or many OA lesions recognised clinically in man the upper zones have became afflicted with deep fissures or erosions so that unravelled or degraded PGs are probably extruded by transport through a continuum of torn collagen network out through the disrupted surface layers of cartilage.

Elasticity calculations of the mechanical testing techniques provide a relative index of instantaneous mechanical behaviour without interpretation of molecular or ultrastructural causes. The technique was reliable and repeatable but is not designed to estimate absolute values of true, elastic mechanical properties of cartilage as discussed by Mow et al. ${ }^{25}$

An increase in stiffness with degradation of cartilage seems contrary to clinical observations in man. ${ }^{26}$ However, this is a very early arthritic model at a degree of degradation which is not generally directly observed clinically. Others have reported similar findings in early osteoarthritic and rheumatoid arthritic animal models. ${ }^{27}{ }^{28}$ Further, these measurements have been made in swollen, immersed cartilage. Stiffness is artificially increased ${ }^{29}$ by swelling. And the difference between the arthritic and normal cartilage is accentuated by the swelling (see Table 1).

The most surprising observation in the creep deflection study is evidence against this happening in the early femoral lesion of Pond-Nuki animals, namely, the structural behaviour of increased rather than reduced stiffness on exposure to $0.9 \%$ saline. Although a matter of speculation, this result is explicable by a hypothetical preservation of surface and of tangential zone cartilage collagen network relative to that in the middle zones. The surface regions would be expected, before PG loss occurs, to become the major bulwark of resistance against PG swelling pressure no longer resisted in midzonal sites. This resistance to the surface indentation could logically be increased within the border zone above expanded middle zones still containing their native PG concentrations. Previous zonal studies on thin tangential sections of cartilage ${ }^{2}$ showed the highest water content of OA cartilage to be in central zones, and studies of shear forces generated on impaction were severest in deep zones. ${ }^{30}$ These data raise the possibility that selective early damage to the middle and/or deep zonal collagen network might lead to cartilage swelling and surface stiffening prior to surface ulceration and softening.

Additional or alternative factors may cause the stiffness observed in our experiments. That is, cartilage surface PGs, when exposed in the saline bath to an excess of $\mathrm{Na}^{+}$ions, were found by Parsons and Black $^{13}$ to contract, probably owing to shielding and neutralisation of PG anionic sites. ${ }^{30}$ If these PGs become attached to collagen fibril bundles, the surface collagen network should contract and stiffen in all the samples, ${ }^{31}$ but stiffen more in the OA cartilage already under a tensile stress from underlying 'oedema.' These postulates, relevant to the current data, are still highly speculative. Finally, in the Pond-Nuki model evidence for early acceleration of collagen synthesis in the destabilised knee was obtained. ${ }^{32}$ Whether hypothetical thickening of collagen fibre bundles could have been sufficient to explain our stiffening of the surface layers in 4 weeks remains undetermined.

Pioneering work on the role of constituents in the biphasic mechanical behaviour of cartilage ${ }^{33}{ }^{34}$ suggests that the intrinsic modulus can be separated from the diffusion effects of fluid flow on cartilage behaviour. Such methods might be able to define some of the cause-and-effect relationships suggested by the authors of that study. The mechanical methods 
employed here simply reflect the behaviour of the cartilage as a 'black box' without regard to such a phenomenon. Yet these methods remain useful in differentiating normal and abnormal cartilage. ${ }^{35}$

Since the retardation-time spectrum was not significantly altered with these early arthritic changes, except for a vertical shift of the curve, it is possible that this shift simply reflects differences in water content. After full swelling the bounds of behaviour may be defined but not the full spectrum of behaviour. In an attempt to approach the variations caused by immersion a parallel test was run on 12 animals (48 specimens) as follows: specimens were first tested in as close to their in-situ state of hydration as possible by maintaining them in a $100 \%$ humidity chamber during a full creep test as described earlier. After this test the load was relaxed, and the specimens were immersed in $0.9 \%$ saline for $20 \mathrm{~min}$ to regain equilibrium and complete hydration. A second creep test was run on the same spot of the cartilage as the first but in the 'immersed' rather than 'moist' state. Values were compared (Table 1). Immersion affected the experimental specimens more than the normal and thus accentuated the differences between the groups. Although the differences were still statistically significant, and the arthritic cartilage was stiffer in the moist state than in the immersed, the level of significance was much greater for the immersed specimens. Although immersion does not reflect normal, in-situ behaviour, it does describe the probable bounds for that behaviour and provides an apparently more sensitive means of testing for early arthritic changes.

The PG study merely confirmed that, despite the mild histological alterations that we could not separate temporally the evidence of torn collagen network from the appearance of a disturbance in PG aggregation. These findings are subtle and it should be emphasised that there is no detectable overall reduction in size of PG subunits, as measured either by Sepharose $2 \mathrm{~B}$ exclusion ${ }^{6}{ }^{7}$ or by analytical ultracentrifugation. Previous studies indicate that PG aggregate size in the early. Pond-Nuki animals was found to be slightly reduced by 2 methods of analytical ultracentrifugation on A1 fractions from tibial eroded cartilage. Furthermore, evidence for shortened PG core protein was recently found. Both the capacity for A1D1D1 fractions (aggregate portions) to reassociate and the results of chromatographic experiments in the presence of hyaluronic acid have led to the conclusion ${ }^{36}{ }^{38}$ that the hypothetical cleavage of the core protein (A1 preparations) occurs pregressively from the outer end of the subunit molecule. These changes are compatible with an enzymic disturbance of synovial or chondrocytic origin at an early stage in this dog model.
The authors are grateful to Oscar Gans for technical skills in measuring cartilage volumes, to Dr Julio C. Pita for helpful suggestions and advice on proteoglycan analysis, and to the Florida Orthopaedic Society for their research support.

This work was supported by NIH Grant AM-08662, the Research Service of the Veterans Administration and the W. L. McKnight Arthritis Research Fund.

\section{References}

1 Bolet A J, Nance J L. Biochemical findings in normal and osteoarthritic articular cartilage. II. Chondroitin sulfate concentration and chain length, water, and ash content.J Clin Invest 1966; 45: 1170-7.

2 Maroudas A, Venn M. Chemical composition and swelling of normal and osteoarthritic femoral head cartilage. Ann Rheum Dis 1977; 36: 399-406.

3 Mankin $\mathrm{H} \mathrm{J}$, Thrasher A Z. Water content and binding in normal and osteoarthritic human articular cartilage. $J$ Bone Joint Surg 1975; 57A: 76-80.

4 Pond M J, Nuki G. Experimentally induced osteoarthritis in the dog. Ann Rheum Dis 1973; 32: 387-8.

5 Gilbertson E M M. Development of periarticular osteophytes in experimentally induced osteoarthritis in the dog. Ann Rheum Dis 1975; 34: 12-25.

$6 \mathrm{McDevitt} \mathrm{C}$, Muir $\mathrm{H}$. Biochemical changes in the cartilage of the knee in experimental and natural osteoarthrosis in the dog. J Bone Joint Surg 1976; 58B: 94-101.

7 McDevitt C, Muir H, Eyre D. Macromolecular biochemistry of cartilage in the initial stages of experimental canine osteoarthritis. In: Nuki G, ed. The aetiopathogenesis of osteoarthritis. London: Pitman, 1980: chapter 6.

8 Kempson G E, Spivey C J, Swanson S A V, Freeman M A R. Patterns of cartilage stiffness on normal and degenerate human femoral heads. J Biomech 1971; 4: 597-609.

9 Brandt K D. Enhanced extractability of articular cartilage proteoglycans in osteoarthritis. Biochem $J$ 1974; 143: 475-8.

10 Moskowitz R W, Howell D S, Goldberg V M, Muniz O, Pita J C. Cartilage proteoglycan alterations in an experimentally induced model of rabbit osteoarthritis. Arthritis Rheum 1979; 22: $155-63$.

11 McDevitt C A, Billingham M E, Muir H. An in vivo study of the metabolism of the proteoglycans in experimental osteoarthritic and normal articular cartilage and the intervertebral disc. Semin Arthritis Rheum 1981; 10 (suppl 1): 17-8.

12 Meachim G. Light microscopy of India ink preparations of fibrillated cartilage. Ann Rheum Dis 1972; 31: 457-64.

13 Parsons J R, Black J T. The viscoelastic shear behavior of normal rabbit articular cartilage. J Biomech 1976; 9: 1-9.

14 Duncan R C, Knapp R G, Miller M L. Introductory biostatistics for the health sciences. New York: Wiley, 1977: 78-88.

15 Sajdera S W, Hascall V C. Proteinpolysaccharide complex from bovine nasal cartilage. A comparison of low and high shear extraction procedures. J Biol Chem 1969; 244: 77-87.

16 Oegema T R, Hascall V C, Dziewiatkowski D D. Isolation and characterization of proteoglycans from the Swarm rate chondrosarcoma.J Biol Chem 1975; 250: 151-9.

17 Pearson J P, Mason $R$ M. The stabilty of bovine nasal cartilage proteoglycans during isolation and storage. Biochim Biophys Acta 1977; 498: 176-88.

18 Hascall V C, Heinegard D. Aggregation of cartilage proteoglycans. I. The role of hyaluronic acid. J Biol Chem 1974; 249: 4232-41.

19 Altman R D, Pita J C, Howell D S. Degradation of proteoglycans in human osteoarthritic cartilage. Arthritis Rheum 1973; 16: 179-85.

20 Dische Z. A new specific colour reaction of hexuronic acids. $J$ Biol Chem 1947; 167: 189-98. 
21 Bitter T, Muir H. A modified uronic acid carbazole reaction. Anal Biochem 1962; 4: 330-4.

22 Pita J C, Muller F J. Ultracentrifugal study of polydisperse and paucidisperse biological systems using capillary microcells. Biochem J 1973; 12: 2656-65.

23 Pita J C, Muller F J, Oegema T R, Hascall V C. Determination of sedimentation coefficient distributions for cartilage proteoglycans. Arch Biochem Biophys 1978; 186: 66-76.

24 Lemperg R, Larsson S E, Hjertquist $S \quad O$. The glycosaminoglycans of bovine articular cartilage. I. Concentration and distribution in different layers in relation to age. Calcif Tissue Res 1974; 15: 237-51.

25 Mow V C, Lai W M, Homes M H 4. Advanced theosetical and experimental techniques in cartilage research. In: Huiskes $\mathbf{R}$, van Campen D, De Wijn J. ed. Biomechanics: principles and applications. The Hague/Boston/London: Nijhoff, 1982: 47-74.

26 Hayes W C, Keer L M, Herrmann G, Mockros L F. A mathematical analysis for indentation tests of articular cartilage. J Biometry 1972; 5: 541-53.

27 Steinberg M E. Laboski D A, Parsons J R, Black J. Changes in mechanical properties of articular cartilage in antigen-induced arthritis. Transactions of the 23rd Annual Meeting: Orthopedic Research Society, Chicago 1977; 2: 79.

28 Parsons J R, Simon W H, Black J. Viscoelastic shear behavior of viable articular cartilage after quantitative enzymolysis:
Hyaluronidase. Transactions of the 23rd Annual Meeting: Orthopedic Research Society, Chicago 1977; 2: 78.

29 Parsons J R, Black J. Mechanical behavior of articular cartilage: Quantitative changes with alteration of ionic environment. J Biochem 1979; 12: 765.

30 Mow V C, Myers E R, Roth V. Investigation of cartilage collagenproteoglycan interaction via its swelling behavior. Transactions of the 26th Annual Meeting: Orthopedic Research Society, Chicago 1980; 2: 40.

31 Armstrong C G, Schoenbeck J, Moss G, Mow V C, Wirth C R. Characterization of impact-induced microtrauma to articular cartilage. In: Mow V C, ed. Transactions of the American Society of Mechanical Engineering. New York: American Society of Mechanical Engineering, 1980.

32 Eyre D R, McDevitt C A, Muir H. Collagen biosynthesis in control and fibrillated articular cartilage. Ann Rheum Dis 1975; 34: 138-40.

33 Mow V C. Biphasic Rheological Properties of Cartilage. Bull Hosp Joint Dis 1977; 38: 121.

34 Armstrong C G, Mow V C, Wirth C R, Lai W M. Variations in the intrinsic mechanical properties of human articular cartilage with age, degeneration and water content. Transactions of the 26th Annual Meeting: Orthopedic Research Society, Chicago. 1980; 5: 36.

35 Parsons J R, McManus E, Johnson E. Time dependent histologic and mechanical alterations of articular cartilage with joint sepsis. Transactions of the 28th Annual Meeting: Orthopedic Research Society, Chicago. 1982; 7: 217. 